\title{
Perceptions On Reciprocal Peer Teaching Among Medical Students As Learners And As Tutors
}

This article was published in the following Dove Press journal:

Advances in Medical Education and Practice

\author{
Saad Mohammed AIShareef \\ Abdulrahman Yousef \\ Aldayel \\ Hamid Mohammed \\ Alghamdi \\ Mohammed Buraik \\ Alosaimi (i) \\ Muteb Mousa Alharbi \\ Abdulaziz Abdulrahman \\ Aldayel (iD) \\ Hamad Abdulaziz \\ Alhussain (D) \\ Department of Medicine, College of \\ Medicine, Imam Mohammad Ibn Saud \\ Islamic University (IMSIU), Riyadh, Saudi \\ Arabia
}

Objectives: The College of Medicine at Imam University has incorporated reciprocal peerteaching into the curriculum in the form of peer-led seminars. The aim was to evaluate this program and ascertain student perceptions.

Methods: A cross-sectional survey of medical students attached to the Internal Medicine I and II courses was conducted in 2018. The questionnaire evaluated perceptions about the peer-teaching program, tutors' knowledge, skills and attitudes, both from a student and a tutor perspective.

Results: Based on a $63 \%$ response rate from a total of 410 students, $34.5 \%$ of learners agreed that peer-tutoring was the most effective method of clinical teaching and $30.3 \%$ disagreed. More students reported that peer-led seminars did not prepare them for their exams (38.4\%) compared to those who reported it did (27.9\%). More than $40 \%$ of participants reported the tutors were approachable, created a welcoming learning environment and provided targeted information. From a tutor perspective, more than $70 \%$ of participants reported that they developed personally and professionally, improved their collaborative, communication, tutoring and presentation skills and confidence. Female students reported they benefited more as tutors compared to male students.

Conclusion: Students regard obligatory reciprocal peer-teaching in the form of peer-led seminars as similar to faculty teaching and an overwhelming majority report that they benefit both personally and professionally from leading seminars. As doctors are expected to teach and train younger generations, medical schools should prepare all students for such roles. A system that provides an opportunity for every student to become a peer-teacher can fulfil this need.

Keywords: curriculum, peer group, students, medical, teaching methods, undergraduate medical education

\section{Introduction}

Peer-teaching in general improves academic achievement, ${ }^{1}$ although there is equivocal evidence that in a healthcare setting it results in better academic performance based on objective outcome measures. ${ }^{2}$ Furthermore, it offers numerous other benefits not only to the tutees but to the peer tutors themselves ${ }^{3}$ and the institutions ${ }^{4}$ it trains leadership, confidence skills and ability to provide effective feedback, it enhances intrinsic motivation, and it offers alternative methods of studying. 5

It appears there is an increasing adoption of peer teaching in undergraduate medical schools, in many instances as part of the formal curriculum. ${ }^{6}$ In some countries, this is encouraged by the relevant regulatory bodies, such as the General
Correspondence: Saad Mohammed AlShareef

Department of Medicine, College of Medicine, Imam Mohammad Ibn Saud Islamic University (IMSIU), PO Box 7544, Riyadh 13317-4233, Saudi Arabia

Email drsaad32I@hotmail.com 
Medical Council in the United Kingdom, ${ }^{7}$ as a recognition that it helps students prepare to become educators and supervisors, ${ }^{6}$ roles and responsibilities that are required from most modern doctors. ${ }^{7,8}$

Despite the positive attitude towards peer-teaching, implementation and subsequent monitoring requires careful consideration. ${ }^{2}$ Tutees may experience stress when pairing them with higher-achieving peer-tutors, ${ }^{9}$ and students in higher education may worry about their peer-tutors teaching skills and effectiveness. ${ }^{10,11}$ It is acknowledged that peer-tutors should receive some form of training, ${ }^{2}$ and there is still a question as to whether peerteaching should remain voluntary or if all students should be expected to have teaching roles. ${ }^{2}$

In the Kingdom of Saudi Arabia, preparing doctors for their future roles as teachers is an essential component of a national competence framework developed by medical schools to guide curriculum design and assessment. ${ }^{12}$ The College of Medicine at Al-Imam University, Saudi Arabia, was founded in 2007, it followed an innovative approach to medical education with a curriculum that was developed by a committee consisting of national and international experts. ${ }^{13}$ The benefits of peer-teaching in improving learning, communication and teamwork, teaching skills, and knowledge ${ }^{14}$ were acknowledged early in the design and hence reciprocal peer-teaching became an integral part of the curriculum, alongside tutor-led lectures, case scenarios, and tutorials. All students are required to lead seminars and discussions on pre-determined topics starting from their 2nd year all the way to the 5th final year. Although there is merit in other forms of peer-teaching, such as non-reciprocal or near-peer ${ }^{1}$ or when performed by selected few purposefully trained students, ${ }^{4}$ our institution considered it was a unique opportunity to expose all students to engage in teaching and thus potentially benefit from such role.

The aim of the study was to evaluate the peer-teaching program as perceived by the medical students. The objectives were to survey medical students as to their perceptions of peer-teaching in general, identify perceived benefits, and evaluate if the organizational support is adequate, both from a tutor and a student perspective.

\section{Materials And Methods}

This descriptive cross-sectional survey examined perceptions of students and interns about the peer-teaching program using a questionnaire disseminated via email on November 2018.

\section{Sampling Procedures}

The sample population was selected via convenience sampling; all 4th and 5th year medical students and medical interns attached to the Internal Medicine I and II rotations were eligible and asked to participate. Although students actively participate in reciprocal peer-teaching, interns have completed their training and are attached to clinical firms before becoming fully registered doctors. They were included because they could offer insight into the lasting perceptions of peer-teaching.

\section{Reciprocal Peer-Teaching}

Students rotate through 5-10 placements per year in groups of approximately 50 divided into two sub-groups. Reciprocal peer-teaching, starts in the 2nd year of study, is in the form of small group seminars where a lead student presents a topic to their subgroup and directs the further discussion. Students are given the topic and the learning objectives for the session and there are otherwise no strict guidelines for the format of either the presentation or the discussion. Students are free to implement their own teaching methods, although the sessions invariably involve a slide presentation and answering questions from the other students. All students present at least once per placement, and the subject topic and objectives are pre-determined within the curriculum focusing on knowledge rather than clinical skills. The seminars last 1-2 hrs, depending on the placement and year of study, and a faculty member is present as a strict observer with no active involvement during the presentation or discussion.

Formal preparation for this role is through two modules: The Learning Skills II course during their 1st year, where the students learn about presentation skills, and the Evidence-Based Medicine course during their second year, where they learn how to identify and present relevant evidence clearly and concisely. The students prepare for these seminars during their own study time and are given contacts to seek help and support from faculty members throughout the course. There are no specific learning goals relating to the peer-teaching program itself, only those defined by the individual topics presented, and a faculty member is a passive observer during the sessions to provide informal feedback at the end of each session to help the student to identify their strengths and areas to focus on relating to their presentation and teaching skills, as well as the topic coverage. 


\section{Survey Design}

A 39-item questionnaire (Q1-Q39) with responses on a 5point Likert scale (strongly disagree to strongly agree) was devised by panel of educators to explore learners' general perceptions, perceptions of tutors' knowledge, skills and attitudes, and organizational support, as well tutors' perceived benefits and support. The questionnaire was based on previous reports in the literature (Q1-3, Q5-6, Q9-15, Q21, Q23-25, Q27, Q34-35), ${ }^{4,15}$ to allow for generalizability and comparison with other studies. It has two parts requiring responses as learners (general perceptions, tutors' knowledge, tutors' skills, tutors' attitudes, organizational support), and as tutors (own knowledge, own skills, own attitudes, organizational support), and there is also a freetext option. Content validity was addressed by including questions on all domains of benefits (knowledge, skills, and attitudes) and incorporating questions used in other studies.

\section{Statistics}

Analysis was performed using Jamovi v 0.9.5 software. Answers were given a score ("Strongly disagree" $=1$, "Disagree"=2, "Neither disagree or agree"=3, "Agree"=4, "Strongly Agree"=5). Descriptive statistics in the form of percentages and medians were used. For descriptive analysis, results were described as students disagreeing with a statement (included both "strongly disagree" and "disagree" responses) and agreeing with a statement (included both "agree" and "strongly agree" responses). A MannWhitney $U$-test was used to compare two independent groups (female-male), and the Kruskal-Wallis for more than 2 independent groups (year of study). The Wilcoxonsigned rank test was used for comparing two paired samples (different questions of the questionnaire), and the Friedman test for comparing more than two paired samples. Spearman correlation coefficients were used to identify correlations between various questions. Level of significance was set at alpha $=0.05$. A Cronbach alpha was calculated to evaluate internal consistency.

\section{Ethical Considerations}

The study was reviewed and approved by the internal review board (IRB) of Al-Imam Muhammad Ibn Saud Islamic University. All study participants were given information about the study and they indicated their consent by completion of the questionnaire. Data were collected and analyzed anonymously to preserve privacy and confidentiality.

\section{Results}

Sixty-three percent (258/410) of students responded. Fifty percent were year 4 students (Table 1) and $85.7 \%$ male $(n=221)$. Only year 4 had female students at the time of the study, 40 in total, resulting in a $92.5 \%$ response rate for female students and $59.7 \%$ response rate for male students. Learners' perceptions of the peer-teaching in general are shown in Table 2, of the peer-tutors and organizational support in Table 3. Peer-tutors' perceptions about themselves and of organizational support are shown in Table 4. The section relating to learners' perceptions (general perceptions, peer-teachers, and organizational support) has good internal consistency with a Cronbach's alpha of 0.912, and so did the section on tutors' perceptions (Cronbach's alpha of 0.935).

\section{Learners' General Perceptions About The Peer Teaching}

Eighty-nine (34.5\%) learners felt peer-tutoring was the most effective method of clinical teaching (agreed or strongly agreed) and $78(30.3 \%)$ disagreed or strongly disagreed (Q1, Table 2). Most of the other responses had a similar distribution except for Q7, where more students felt peer-led seminars did not prepare them for their exams (38.4\%) compared to those who felt it did (27.9\%). Friedman test and pairwise comparisons (DurbinConover) confirmed that only the responses to that question were different among the questions on general perceptions $(P<0.003)$. Cronbach's alpha was 0.886 for this set of questions.

Only four students responded to the free-text question if they had anything else to add:

One thing needs to be well-established and well-understood: any Basic information or learning process must be given by a tutor NOT by peers or students. Peers and

Table I Response Rates Based On Year Of Study

\begin{tabular}{|c|c|c|c|c|}
\hline Levels & $n$ & Respondents & $\begin{array}{l}\% \text { Of } \\
n\end{array}$ & $\begin{array}{l}\text { Cumulative } \\
\%\end{array}$ \\
\hline $\begin{array}{l}4 \text { th year medical } \\
\text { students }\end{array}$ & 180 & 129 & $71.6 \%$ & $50.0 \%$ \\
\hline $\begin{array}{l}\text { 5th year medical } \\
\text { students }\end{array}$ & 110 & 94 & $85.5 \%$ & $86.4 \%$ \\
\hline Medical interns & 120 & 35 & $29.2 \%$ & $100.0 \%$ \\
\hline
\end{tabular}

Notes: Year 4 students were 140 males and 40 females, of which 37 responded. All other years are comprised solely of male students. Medical interns are effectively 6th year students and do not participate in peer teaching.

Abbreviation: $n$, total number of students at that year. 
Table 2 Learners' General Perceptions Of Peer-teaching

\begin{tabular}{|c|c|c|c|c|c|c|c|c|c|c|c|}
\hline \multicolumn{2}{|c|}{ Question } & \multicolumn{2}{|c|}{ SD } & \multicolumn{2}{|l|}{$\mathbf{D}$} & \multicolumn{2}{|l|}{$\mathbf{N}$} & \multicolumn{2}{|l|}{ A } & \multicolumn{2}{|c|}{ SA } \\
\hline & & $n$ & $\%$ & $n$ & $\%$ & $n$ & $\%$ & $n$ & $\%$ & $n$ & $\%$ \\
\hline I & Peer tutoring is the most effective method of clinical teaching ${ }^{\mathrm{a}}$ & 20 & 7.8 & 58 & 22.5 & 91 & 35.3 & 67 & 26.0 & 22 & 8.5 \\
\hline 2 & I prefer being taught by peer tutors compared to faculty teachers & 27 & 10.5 & 60 & 23.3 & 85 & 32.9 & 65 & 25.2 & 21 & 8.1 \\
\hline 3 & $\begin{array}{l}\text { I am more willing to engage in sessions taught by peer tutors compared to } \\
\text { faculty teachers }\end{array}$ & 20 & 7.8 & 56 & 21.7 & 92 & 35.7 & 69 & 26.7 & 21 & 8.1 \\
\hline 4 & I learn at least as well when taught by peer teachers compared to faculty & 24 & 9.3 & 61 & 23.6 & 84 & 32.6 & 64 & 24.8 & 25 & 9.7 \\
\hline 5 & I feel more confident learning from peer tutors compared to faculty teachers & 27 & 10.5 & 63 & 24.4 & 81 & 31.4 & 61 & 23.6 & 26 & 10.1 \\
\hline 6 & $\begin{array}{l}\text { I am satisfied with the peer-tutored clinical teaching that I received in internal } \\
\text { medicine }\end{array}$ & 21 & 8.1 & 59 & 22.9 & 93 & 33.7 & 69 & 20.9 & 16 & 7.0 \\
\hline 7 & $\begin{array}{l}\text { The peer-tutored teaching which I received in internal medicine is enough to } \\
\text { prepare me for my clinical year exams. }\end{array}$ & 40 & 15.5 & 59 & 22.9 & 87 & 33.7 & 54 & 20.9 & 18 & 7 \\
\hline 8 & $\begin{array}{l}\text { I spent more time out of the classroom reading on what I learnt during a } \\
\text { peer-led seminar than I did after other faculty-led teaching activities - put I } \\
\text { for less time, } 3 \text { for equal time and } 5 \text { for more time }\end{array}$ & 27 & 10.5 & 51 & 19.8 & 93 & 36.0 & 46 & 17.8 & $4 I$ & 15.9 \\
\hline
\end{tabular}

Note: ${ }^{a}$ Female students agreed less than males in these questions.

Abbreviations: SD, strongly disagree; D, disagree; N, neither agree or disagree; A, agree; SA, strongly agree; n, number; \%, percentage of row totals.

Table 3 Learner's Perceptions Of Peer-Tutors And Organizational Support

\begin{tabular}{|c|c|c|c|c|c|c|c|c|c|c|c|}
\hline \multicolumn{2}{|c|}{ Question } & \multicolumn{2}{|c|}{ SD } & \multicolumn{2}{|l|}{ D } & \multicolumn{2}{|l|}{$\mathbf{N}$} & \multicolumn{2}{|l|}{ A } & \multicolumn{2}{|c|}{ SA } \\
\hline & Tutors Knowledge & \multirow{2}{*}{$\begin{array}{l}n \\
13\end{array}$} & \multirow{2}{*}{$\begin{array}{l}\% \\
5.0\end{array}$} & \multirow{2}{*}{$\begin{array}{l}n \\
43\end{array}$} & \multirow{2}{*}{$\begin{array}{l}\% \\
16.7\end{array}$} & \multirow{2}{*}{$\begin{array}{l}n \\
101\end{array}$} & \multirow{2}{*}{$\begin{array}{l}\% \\
39.1\end{array}$} & \multirow{2}{*}{$\begin{array}{l}n \\
77\end{array}$} & \multirow{2}{*}{$\begin{array}{l}\% \\
29.8\end{array}$} & \multirow{2}{*}{$\begin{array}{l}n \\
24\end{array}$} & $\%$ \\
\hline 9 & The tutors' knowledge was appropriate for the required level of teaching & & & & & & & & & & 9.3 \\
\hline 10 & $\begin{array}{l}\text { They provided appropriate information and resources that targeted my } \\
\text { needs }^{\mathrm{a}, \mathrm{b}}\end{array}$ & 13 & 5.0 & 47 & 18.2 & 93 & 36.0 & 79 & 30.6 & 26 & 10.1 \\
\hline II & The tutors addressed learning objectives relevant to the exam ${ }^{\mathrm{b}}$ & 24 & 9.3 & 53 & 20.5 & 87 & 33.7 & 71 & 27.5 & 23 & 8.9 \\
\hline & Tutors Skills & & & & & & & & & & \\
\hline 12 & The tutors employed effective teaching strategies during the seminars ${ }^{\mathrm{a}, \mathrm{b}}$ & 16 & 6.2 & 50 & 19.4 & 97 & 37.6 & 76 & 29.5 & 19 & 7.4 \\
\hline 13 & $\begin{array}{l}\text { The tutors were able to explain concepts and answer questions that were } \\
\text { clinically relevant } \mathrm{t}^{\mathrm{a}, \mathrm{b}}\end{array}$ & 9 & 3.5 & 52 & 20.2 & 96 & 37.2 & 67 & 26.0 & 34 & 13.2 \\
\hline & Tutors Attitudes & & & & & & & & & & \\
\hline 14 & Tutors were approachable and happy to answer questionsa & 13 & 5.0 & 45 & 17.4 & 80 & 31.0 & 83 & 32.2 & 37 & 14.3 \\
\hline 15 & Tutors created a welcoming learning environment $\mathrm{t}^{\mathrm{a}, \mathrm{b}}$ & 14 & 5.4 & 46 & 17.8 & 79 & 30.6 & 78 & 30.2 & 41 & 15.9 \\
\hline & Organizational Support & & & & & & & & & & \\
\hline 16 & The seminar rooms were appropriate for the activity & 13 & 5.0 & 49 & 19.0 & 82 & 31.8 & 73 & 28.3 & 41 & 15.9 \\
\hline 17 & The timing of the seminars was appropriate & $\mathrm{II}$ & 4.3 & 47 & 18.2 & 91 & 35.3 & 71 & 27.5 & 38 & 14.7 \\
\hline 18 & We should have more peer-led seminars & 29 & 11.2 & 45 & 17.4 & 97 & 37.6 & 59 & 22.9 & 28 & 10.9 \\
\hline 19 & There was not enough time during a seminar to cover all the objectives & 18 & 7.0 & 48 & 18.6 & 96 & 37.2 & 68 & 26.4 & 28 & 10.9 \\
\hline
\end{tabular}

Notes: ${ }^{a}$ Female students agreed less compared to males, and ${ }^{b}$ Medical interns more likely to agree than other students.

Abbreviations: SD, strongly disagree; D, disagree; N, neither agree or disagree; A, agree; SA, strongly agree; n, number; \%, percentage of row totals.

students may engage in debating issues or subjects that are not considered basic or important-to-know.

The issue is the preparation of some students, it minimizes the benefit of peer teaching

At the time you are preparing yourselves for the seminar presentation, you can study a lot of useful subjects instead.
I'll agree with the seminar if it's only one time per course

\section{Learners' Perceptions On The Peer Teachers}

The learners were generally satisfied with the level of knowledge, skills and attitudes of the peer tutors, since a higher 
Table 4 Peer-Tutors' Perceptions

\begin{tabular}{|c|c|c|c|c|c|c|c|c|c|c|c|}
\hline \multicolumn{2}{|c|}{ Question } & \multicolumn{2}{|c|}{ SD } & \multicolumn{2}{|l|}{ D } & \multicolumn{2}{|l|}{$\mathbf{N}$} & \multicolumn{2}{|l|}{ A } & \multicolumn{2}{|c|}{ SA } \\
\hline & & n & $\%$ & n & $\%$ & n & $\%$ & n & $\%$ & $n$ & $\%$ \\
\hline & Own Knowledge & & & & & & & & & & \\
\hline 20 & I had the opportunity to consolidate my own knowledge. & 4 & 1.6 & 14 & 5.4 & 69 & 26.7 & 123 & 47.7 & 48 & 18.6 \\
\hline \multirow[t]{2}{*}{21} & $\begin{array}{l}\text { Being a clinical peer tutor has increased my confidence in my own exam } \\
\text { performance }^{a}\end{array}$ & 2 & 0.8 & 19 & 7.4 & 62 & 24 & 107 & 41.5 & 68 & 26.4 \\
\hline & Own Skills & & & & & & & & & & \\
\hline 22 & $\begin{array}{l}\text { Being a clinical peer tutor has increased my confidence in my tutoring and } \\
\text { presentation skills }\end{array}$ & 4 & 1.6 & 14 & 5.4 & 53 & 20.5 & 114 & 44.2 & 73 & 28.3 \\
\hline 23 & $\begin{array}{l}\text { I have a better understanding of teamwork and understanding roles within } \\
\text { the team }{ }^{\text {a }}\end{array}$ & 6 & 2.3 & 22 & 8.5 & 51 & 19.8 & 104 & 40.3 & 75 & 29.1 \\
\hline 24 & My communication skills with my colleagues has improved ${ }^{\mathrm{a}}$ & 5 & 1.9 & 17 & 6.6 & 49 & 19 & 109 & 42.2 & 78 & 30.2 \\
\hline 25 & I can collaborate better with my colleagues ${ }^{\mathrm{a}}$ & 5 & 1.9 & 14 & 5.4 & 53 & 20.5 & 106 & $4 I . I$ & 80 & 31 \\
\hline \multirow[t]{2}{*}{26} & Teaching is a very hard skill and I felt myself getting better each time ${ }^{a}$ & 2 & 0.8 & 13 & 5 & 55 & 21.3 & 115 & 44.6 & 73 & 28.3 \\
\hline & Own Attitudes & & & & & & & & & & \\
\hline 27 & I am a better role model to my peers ${ }^{\mathrm{a}}$ & 6 & 2.3 & 20 & 7.8 & 82 & 31.8 & 90 & 34.9 & 60 & 23.3 \\
\hline 28 & I gained many benefits from this experience and I am willing to repeat it ${ }^{\mathrm{a}}$ & 7 & 2.7 & 12 & 4.7 & 71 & 27.5 & 99 & 38.4 & 69 & 26.7 \\
\hline 34 & I have developed both personally and professionally & 4 & 1.6 & 17 & 6.6 & 47 & 18.2 & 112 & 43.4 & 78 & 30.2 \\
\hline \multirow[t]{2}{*}{35} & $\begin{array}{l}\text { Being a clinical skills peer tutor has made me consider pursuing teaching in } \\
\text { the future }^{\mathrm{a}}\end{array}$ & 13 & 5 & 27 & 10.5 & 70 & 27. 1 & 83 & 32.2 & 65 & 25.2 \\
\hline & Organizational Support & & & & & & & & & & \\
\hline 29 & The seminar rooms were appropriate for the activity ${ }^{a}$ & 9 & 3.5 & 24 & 9.3 & 80 & 31 & 89 & 34.5 & 56 & 21.7 \\
\hline 30 & The timing of the seminars was appropriate ${ }^{a}$ & 10 & 3.9 & 29 & 11.2 & 79 & 30.6 & 84 & 32.6 & 56 & 21.7 \\
\hline 31 & We should have more peer-led seminars ${ }^{\mathrm{a}}$ & 15 & 5.8 & 36 & 14 & 66 & 25.6 & 88 & 34. I & 53 & 20.5 \\
\hline 32 & There was not enough time during a seminar to cover all the objectives ${ }^{a}$ & 15 & 5.8 & 39 & I5.I & 68 & 26.4 & 94 & 36.4 & 42 & 16.3 \\
\hline 33 & $\begin{array}{l}\text { The objectives and content to cover in the seminar were clearly and } \\
\text { sufficiently detailed }^{\text {a }}\end{array}$ & 7 & 2.7 & 30 & 11.6 & 74 & 28.7 & 97 & 37.6 & 50 & 19.4 \\
\hline 36 & I think the students benefited from this teaching experience ${ }^{a}$ & 7 & 2.7 & 20 & 7.8 & 64 & 24.8 & 103 & 39.9 & 64 & 34.8 \\
\hline 37 & $\begin{array}{l}\text { The available infrastructure teaching rooms, learning material was } \\
\text { appropriate }^{\mathrm{a}, \mathrm{b}}\end{array}$ & 10 & 3.9 & 33 & 12.8 & 57 & 22.1 & 104 & 40.3 & 54 & 20.9 \\
\hline 38 & I had support from faculty or other peers ${ }^{\mathrm{a}}$ & 15 & 5.8 & 31 & 12 & 56 & 21.7 & 97 & 37.6 & 59 & 22.9 \\
\hline 39 & Overall, I feel I was adequately prepared for this role ${ }^{\mathrm{a}, \mathrm{b}}$ & 6 & 2.3 & 27 & 10.5 & 64 & 24.8 & 91 & 35.3 & 70 & 27.1 \\
\hline
\end{tabular}

Note: ${ }^{a}$ Female students agreed more compared to males, and ${ }^{b} 5$ th year students less likely to agree than other students.

Abbreviations: SD, strongly disagree; D, disagree; N, neither agree or disagree; A, agree; SA, strongly agree; n, number; \%, percentage of row totals.

percentage agreed or strongly agreed with the statements rather than disagree (Table 3). Friedman test revealed there were statistically significant variations, attributed to the questions on the objectives (Q11) and the tutors employing effective teaching methods (Q12), both showing slightly less positive trend in the responses. Spearman rho correlation revealed positive correlation between all these responses. Cronbach's alpha was 0.874 for this set of questions.

\section{Learners' Perceptions On Organizational Support}

Overall, 114 (44.2\%) students thought the facilities were appropriate and $109(42.2 \%)$ that the timing was right
(Table 3). Ninety-six (37.3\%) students felt the allocated time was not enough, and $87(33.8 \%)$ would prefer more seminars compared to $76(28.6 \%)$ who do not. Friedman test and pairwise comparisons (Durbin-Conover) confirmed that there was a difference between all these responses $(P<0.001)$ due to the above questions (Q18, Q19). Spearman rho correlation revealed positive correlation between all these responses. Cronbach's alpha was 0.876 .

\section{Tutors' Perceptions}

Perceptions from a tutor perspective were overwhelmingly positive across all questions relating to perceived benefit (Table 4). Friedman test and pairwise comparisons 
Table 5 Perceptions According To Gender

\begin{tabular}{|c|c|c|c|c|c|c|c|}
\hline Question & Group & $\mathbf{N}$ & Mean & Median & SD & SE & $\mathbf{P}$ \\
\hline \multicolumn{8}{|l|}{ Learners' Perceptions } \\
\hline \multirow[t]{2}{*}{ Peer tutoring is the most effective method of clinical teaching } & Female & 37 & 2.76 & 3 & 0.76 & 0.125 & 0.045 \\
\hline & Male & 221 & 3.1 & 3 & 1.103 & 0.0742 & \\
\hline \multirow[t]{2}{*}{ They provided appropriate information and resources that targeted my needs } & Female & 37 & 2.89 & 3 & 0.774 & 0.127 & 0.014 \\
\hline & Male & 221 & 3.28 & 3 & 1.05 & 0.0706 & \\
\hline \multirow[t]{2}{*}{ The tutors employed effective teaching strategies during the seminars } & Female & 37 & 2.78 & 3 & 0.75 & 0.123 & 0.012 \\
\hline & Male & 221 & 3.18 & 3 & 1.037 & 0.0698 & \\
\hline \multirow{2}{*}{$\begin{array}{l}\text { The tutors were able to explain concepts and answer questions that were } \\
\text { clinically relevant }\end{array}$} & Female & 37 & 2.92 & 3 & 0.795 & 0.131 & 0.027 \\
\hline & Male & 221 & 3.31 & 3 & 1.06 & 0.0713 & \\
\hline \multirow[t]{2}{*}{ Tutors were approachable and happy to answer questions } & Female & 37 & 2.81 & 3 & 0.845 & 0.139 & $<0.001$ \\
\hline & Male & 221 & 3.42 & 4 & 1.091 & 0.0734 & \\
\hline \multirow[t]{2}{*}{ Tutors created a welcoming learning environment } & Female & 37 & 2.97 & 3 & 0.928 & 0.152 & 0.019 \\
\hline & Male & 221 & 3.39 & 3 & 1.126 & 0.0757 & \\
\hline \multirow{3}{*}{$\begin{array}{l}\text { Tutors' Perceptions } \\
\text { Being a peer tutor has increased my confidence in my own exam performance }\end{array}$} & & & & & & & \\
\hline & Female & 37 & 4.16 & 4 & 0.688 & 0.113 & 0.03 \\
\hline & Male & 221 & 3.8 & 4 & 0.947 & 0.0637 & \\
\hline \multirow{2}{*}{$\begin{array}{l}\text { I have a better understanding of teamwork and understanding roles within the } \\
\text { team }\end{array}$} & Female & 37 & 4.24 & 4 & 0.796 & 0.131 & 0.009 \\
\hline & Male & 221 & 3.79 & 4 & 1.029 & 0.0692 & \\
\hline \multirow[t]{2}{*}{ My communication skills with my colleagues has improved } & Female & 37 & 4.22 & 4 & 0.787 & 0.129 & 0.042 \\
\hline & Male & 221 & 3.87 & 4 & 0.983 & 0.0661 & \\
\hline \multirow[t]{2}{*}{ I can collaborate better with my colleagues } & Female & 37 & 4.24 & 4 & 0.796 & 0.131 & 0.028 \\
\hline & Male & 221 & 3.89 & 4 & 0.968 & 0.0651 & \\
\hline \multirow[t]{2}{*}{ Teaching is a very hard skill and I felt myself getting better each time } & Female & 37 & 4.22 & 4 & 0.75 & 0.123 & 0.042 \\
\hline & Male & 221 & 3.9 & 4 & 0.889 & 0.0598 & \\
\hline \multirow[t]{2}{*}{ I am a better role model to my peers } & Female & 37 & 4.08 & 4 & 0.954 & 0.157 & 0.003 \\
\hline & Male & 221 & 3.62 & 4 & 0.981 & 0.066 & \\
\hline \multirow[t]{2}{*}{ I gained many benefits from this experience and I am willing to repeat it } & Female & 37 & 4.11 & 4 & 0.809 & 0.133 & 0.036 \\
\hline & Male & 221 & 3.77 & 4 & 0.989 & 0.0665 & \\
\hline \multirow{2}{*}{$\begin{array}{l}\text { Being a clinical skills peer tutor has made me consider pursuing teaching in the } \\
\text { future }\end{array}$} & Female & 37 & 4.11 & 4 & 0.906 & 0.149 & 0.003 \\
\hline & Male & 221 & 3.54 & 4 & 1.134 & 0.0763 & \\
\hline \multirow[t]{2}{*}{ The seminar rooms were appropriate for the activity } & Female & 37 & 4.24 & 4 & 0.796 & 0.131 & $<0.001$ \\
\hline & Male & 221 & 3.51 & 4 & 1.034 & 0.0696 & \\
\hline \multirow[t]{2}{*}{ The timing of the seminars was appropriate } & Female & 37 & 4.14 & 4 & 0.751 & 0.124 & $<0.001$ \\
\hline & Male & 221 & 3.48 & 3 & 1.085 & 0.073 & \\
\hline \multirow[t]{2}{*}{ We should have more peer-led seminars } & Female & 37 & 4.19 & 4 & 0.908 & 0.149 & $<0.001$ \\
\hline & Male & 221 & 3.38 & 3 & 1.132 & 0.0762 & \\
\hline \multirow[t]{2}{*}{ There was not enough time during a seminar to cover all the objectives } & Female & 37 & 4.19 & 4 & 0.739 & 0.122 & $<0.001$ \\
\hline & Male & 221 & 3.29 & 3 & 1.108 & 0.0745 & \\
\hline \multirow{2}{*}{$\begin{array}{l}\text { The objectives and content to cover in the seminar were clearly and sufficiently } \\
\text { detailed }\end{array}$} & Female & 37 & 4.19 & 4 & 0.845 & 0.139 & $<0.001$ \\
\hline & Male & 221 & 3.49 & 4 & 1.007 & 0.0678 & \\
\hline
\end{tabular}

(Continued) 
Table 5 (Continued).

\begin{tabular}{|c|c|c|c|c|c|c|c|}
\hline Question & Group & $\mathbf{N}$ & Mean & Median & SD & SE & $\mathbf{P}$ \\
\hline \multirow[t]{2}{*}{ I think the students benefited from this teaching experience } & Female & 37 & 4.19 & 4 & 0.845 & 0.139 & 0.003 \\
\hline & Male & 221 & 3.69 & 4 & 1.007 & 0.0677 & \\
\hline \multirow[t]{2}{*}{ The available infrastructure teaching rooms, learning material was appropriate } & Female & 37 & 4.16 & 4 & 0.688 & 0.113 & $<0.001$ \\
\hline & Male & 221 & 3.52 & 4 & 1.098 & 0.0738 & \\
\hline \multirow[t]{2}{*}{ I had support from faculty or other peers } & Female & 37 & 4.05 & 4 & 1.053 & 0.173 & 0.003 \\
\hline & Male & 221 & 3.52 & 4 & 1.134 & 0.0763 & \\
\hline \multirow[t]{2}{*}{ Overall, I feel I was adequately prepared for this role } & Female & 37 & 4.14 & 4 & 0.976 & 0.161 & 0.007 \\
\hline & Male & 221 & 3.68 & 4 & 1.041 & 0.07 & \\
\hline
\end{tabular}

(Durbin-Conover) indicated there was a difference between the answers, mainly because of the different distribution of Q20 (“consolidate my own knowledge”), Q27 ("I am a better role model"), Q28 ("I have gained benefits and willing to repeat it"), and Q35 ("consider teaching in the future"). Spearman rho correlation revealed positive correlation between all these responses. Cronbach's alpha was 0.898 for this set of questions.

Relating to organizational support from a tutor perspective, perceptions were overwhelmingly positive, across all questions (Table 4, Q29-39), except for Q32, where most students felt there was not enough time in the seminars to cover all objectives (52.7\%), and Q21, where students thought they need more peer-led seminars $(54.6 \%$ agree or strongly agree). Friedman test and pairwise comparisons (Durbin-Conover) indicated there was no difference between the answers, except for Q36 ("I think the students benefited from this teaching experience") and Q39 ("I was adequately prepared"), both of which had even more positive responses than the other questions. Spearman rho correlation revealed positive correlation between all the responses. Cronbach's alpha was 0.866 for this set of questions.

A Wilcoxon signed ranked test revealed statistically significant difference between the pairs of the same questions relating to organizational support asked in the learners' (Table 3, Q16-19) and the tutors' (Table 4, Q29-32) sections $(P<0.001)$. Students were more likely to agree or strongly agree to the same questions in the tutors' section.

\section{Gender Comparisons}

Female students were less likely to agree that peer teaching is the most effective method (median $=3, \mathrm{IQR}=2-4$ ) compared to males (median=3, IQR $=2-5)(P=0.045)$, although there was no difference in preferring peer-teaching over faculty $(P=0.536)$ (Table 5$)$. They were also less likely to agree with the questions relating to the peer-tutors' abilities compared to male students $(P<0.030)$ in all questions apart from tutor knowledge $(\mathrm{P}=$ and addressing objectives relevant to the exam).

In contrast, when answering the questionnaire relating to them leading a seminar as a tutor, they had more positive perceptions about the benefits they received in all questions apart from consolidating their own knowledge, confidence in tutoring and presentation, and developing personally and professionally. They also agreed with all the questions on organizational support more than male students $(P<0.007)$.

Across responses only from the 4 th year (since there are currently no female students in the other years), the differences were more pronounced. Female students agreed less that tutor information targeted their needs compared to male students, $\mathrm{p}=0.041$, or that the tutors tackled clinically relevant concepts, $P=0.027$ (females median=3, IQR $=2-3$, males median=3, IQR=3-4 to both questions). They were less likely to agree that tutors were approachable $(P<0.001)$ or that created a welcoming environment $(P=0.001)$ (median=3, compared to males median $=4$ to both questions).

Female tutors from the 4th year cohort had more positive perceptions compared to males of the same 4th year cohort: they agreed more that peer-teaching increased their understanding of teamwork $(P=0.006)$, improved their communication skills $(P=0.036)$ and collaboration $(P=0.042)$. They also felt they were a better role model (median=4, compared to male median=3, $P=0.002$ ), and that they gained benefits $(P=0.002)$. They were also more positive about the infrastructure (appropriateness of the rooms, timing of the seminars, and well-defined objectives, $P<0.001$ ), though they also reported there was not 
enough time $(P<0.001)$. They also felt generally more supported than male students $(P=0.016)$.

\section{Year Of Study Comparisons}

Medical interns were slightly more likely to agree compared to year 4 or year 5 students in the questions about the information targeting their needs $(P=0.009)$, the objectives being relevant to the exam $(P=0.017)$, tutors employing effective methods $(P=0.023)$ and creating a welcoming environment $(P=0.011)$. Year 5 students agreed less in questions about the infrastructure $(P=0.045)$ and being adequately prepared $(P=0.035)$. No differences were found in the other questions.

\section{Discussion}

Reciprocal peer teaching is inadequately addressed in the literature. ${ }^{2,14}$ Although this study is not an interventional comparative study, it addresses this issue by presenting real-world perceptions of a program that does not limit student participation as peer-teachers based on skill or voluntary basis. Even though the students were apprehensive in making firm decisions as to the effectiveness of the peerteaching program, with the majority neither agreeing nor disagreeing (Figure 1), they acknowledged that leading a seminar resulted in improvements in their knowledge, skills, and attitudes. This is in alignment with other literature which suggests that same-level peer teaching has many benefits beyond academic performance ${ }^{17}$ and strengthens the notion that a peer-teaching program does not necessarily need to focus on improving exam results but rather on training students for other roles, and as such it should be accessible to all.

In our study, there was no clear positive perception that peer-teaching was the most effective way to learn, preference over faculty teaching, confidence in learning from peer tutors, being more willing to engage in sessions taught by peer-tutors, and being confident in the knowledge of peer tutors, although there was still an overall positive impression (Figure 1). Peer-teaching is seen in a more positive light by students when the tutors are from more advanced years and specifically selected and trained for this role. ${ }^{4,15}$ Khalid et $\mathrm{al}^{4}$ evaluated a two-year program where preclinical students believed that peer-teaching was the most effective way to learn clinical skills, and this positive attitude was also evident in the questions mentioned. Khalid et al attributed their results to similarities between students and peer tutors in both demographic characteristics and in sharing similar experiences. In our case, peer tutors are not selected based on competitive assessment and actual and perceived competence of the tutors likely plays a larger role than learner-tutor similarities.

Students expect the peer-tutors to be trustworthy, ${ }^{10}$ and judging from the free-text responses, some students do not view their peers as efficient tutors. This is expected in a system where all students become peer-tutors irrespective of commitment or skill. The provision of efficient training is important to enhance the tutoring skills of students. In our institution, students receive training in presentation skills as part of the Learning Skills II course during the 1st year of university, and on how to identify and present relevant evidence as part of the Evidence-Based Medicine course during the 2nd year. Although the majority of students felt supported and prepared for their role, incorporating training on adult education principles and methods as well as more specific issues such as time management, dealing with group dynamics and with

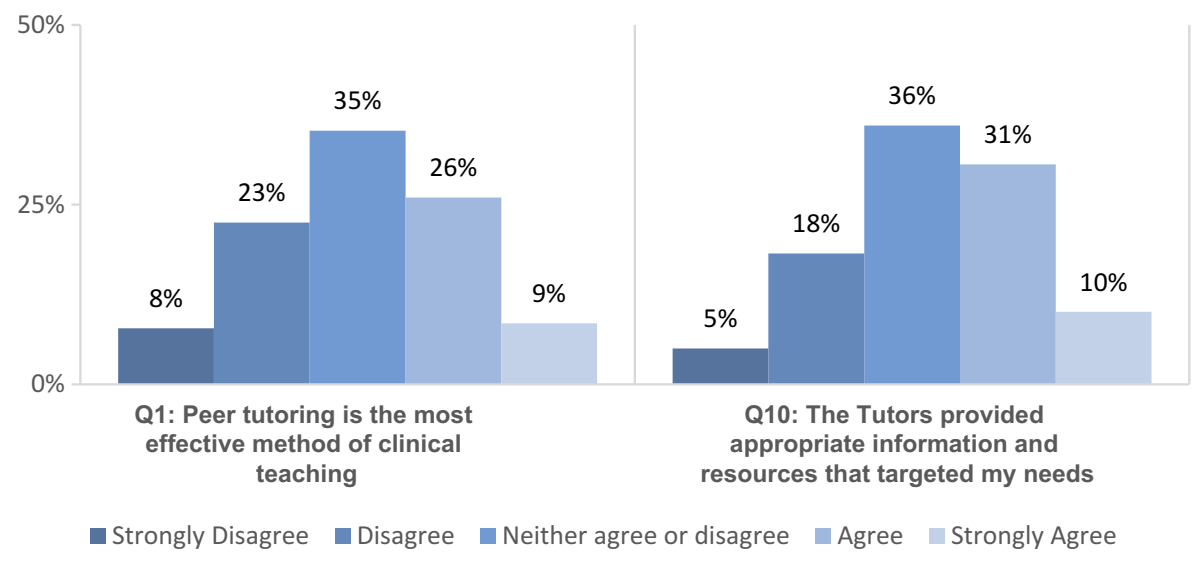

Figure I Responses to sample questions about the program and the tutors. 
learners in difficulty during these courses will likely increase peer-tutor confidence ${ }^{18,19}$ and skills, ${ }^{20}$ and thus improve the perceptions of students. ${ }^{21} \mathrm{~A}$ review of the feedback the students receive at the end of each seminar, which was not explored in this study, may also highlight further areas of improvement.

In our institution, the peer-teaching is reciprocal, and this also likely reduces the effectiveness according to the literature. Leung et $\mathrm{al}^{3}$ report in their systematic review that peer-tutors benefit from enhanced academic performance with a moderate effect size $(\mathrm{d}=0.38)$. However, they advocate shorter and fewer weekly training sessions, more frequent and longer peer-tutoring sessions, and same-sex and same-age non-reciprocal tutoring for maximum effect. Increasing the number and length of peertutoring sessions could be attempted, as many students have expressed a need for both.

Although most of the students had positive perceptions of the knowledge, skills, and attitudes of the tutors, and the peer-tutors in our study felt they were supported for this role (Figure 2), more effort should be placed in elevating the role of the peer-tutors. This is important because peertutors can face a lack of role clarity, ${ }^{22}$ since they want to know which are their responsibilities without taking on extra roles, and they want to be trusted by the students. ${ }^{22}$ The faculty also has a role in ensuring that the students are aware of the trust endowed by the faculty on the peertutors, providing clear goals and expectations to the tutors, and setting up appropriate training so that peer tutoring is performed by knowledgeable and skillful students, usually from more advanced years. ${ }^{22}$ This is an area that should be explored by our institution, possibly through incorporating specific modules on teaching methods as discussed previously.
Peer-tutors have positive opinions about the process and feel that they benefit, both professionally and personally (Figure 2), with improved communication skills, presentation skills, teamwork, and knowledge. Many also report they will consider teaching in the future. These positive perceptions are shared among many students who teach clinical skills ${ }^{4,15-17}$ or even other subjects, such as ECG interpretation, although this is not always associated with an objective improvement in actual performance. ${ }^{18}$ In the study by Khaw and Raw, ${ }^{15}$ more peer-tutors strongly agreed with the above-mentioned benefits compared to our study, and this likely represents the different set-up; year 6 students are offered a medical education elective where they teach year 1-2 students on clinical skills, rather than knowledge as in our institution, and hence the sample population is different (respondents are motivated). The reasons behind these gains are many and relate to motivation, self-monitoring and having to organize the knowledge and retrieve it during the teaching session. ${ }^{18}$

Our students are separated in terms of gender so peerteaching is performed by students of the same group, and same-sex peer-tutoring has been associated with better objective outcomes. ${ }^{3}$ Female students are more likely to identify perceived benefits in our study compared to male students, possibly related to the better academic performance of female students, especially in pre-clinical years. ${ }^{23}$ In contrast, they were also less positive about the abilities of the tutors to be approachable and create a welcoming environment. The reasons are unclear, and other studies have shown conflicting results, from reporting no difference in perceptions between male and female students ${ }^{24}$ to reporting that male students score male presenters more highly ${ }^{25}$ and female students finding peer-assisted learning useful and a safe learning environment; ${ }^{26}$ in contrast to this study, there is no segregation of students by gender during

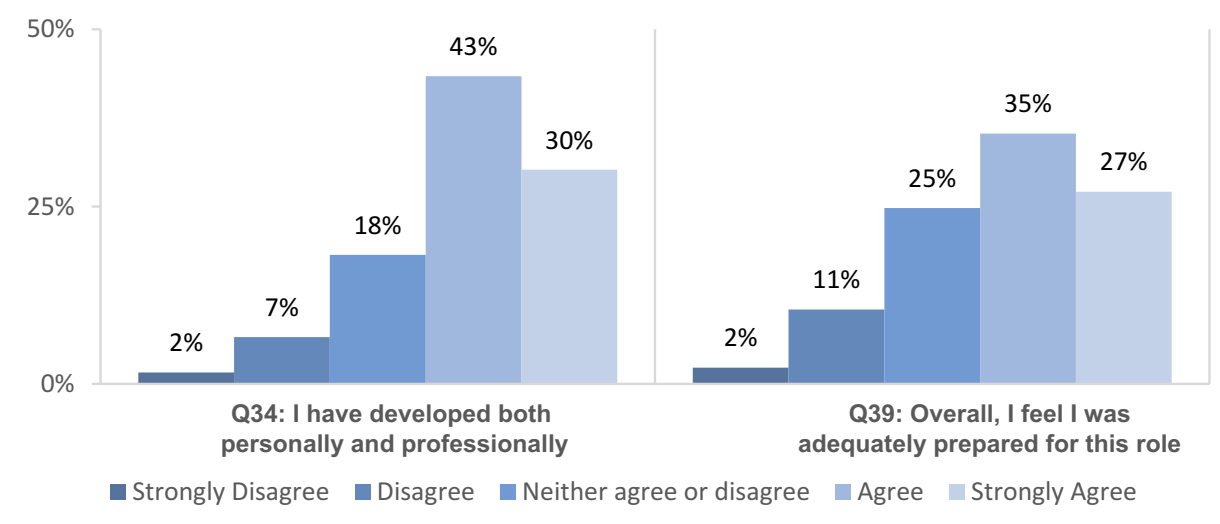

Figure 2 Responses to sample questions from a tutor perspective. 
their studies and the social environment is too different to make meaningful comparisons. Nonetheless, student perceptions are likely influenced by the subtle psychosocial differences between genders, such as that male medical students score higher in loneliness and female students higher in anxiety evaluations, ${ }^{27}$ and by unconscious gender biases in student evaluations of teaching. ${ }^{28}$

The study also included medical interns who have completed their training to gain an understanding of the long-lasting perceived benefits. Compared to 4th and 5th year students who shared similar opinions, medical interns were more positive about the abilities of their peers. This could relate to the low number of medical interns in our study, recollection bias, or reflect true differences in the tutoring abilities of that cohort.

\section{Limitations}

The main limitation of this study is that all students have led a seminar and their views as learners and as tutors are not independent. However, the questionnaire was divided into two sections with clear heading as to whether the questions related to their role as students and as tutors, and the students responded differently with a statistical significance to similar questions asked in both sections. This likely means that the questionnaire was successful in focusing the students to answer from two different perspectives.

The inclusion of a middle response resulted in many of the questions being answered with a neutral response, somewhat limiting our findings. A forced-choice format where the respondent is forced to choose agreement or disagreement provides more meaningful results. ${ }^{29}$

The convenience sampling employed in this study could introduce bias of students responding about their current experiences and not about the peer-teaching in general. Nevertheless, students were recruited from three different years and two placements, thus ensuring a somewhat expansive sample and limiting this bias.

Although the questionnaire has not been used in its exact form in other studies, it has face, external, and construct validity. Questions used in other studies were incorporated, and a panel of educators examined the questions for factorial validity, relevance and clarity. The questionnaire and its individual subsections show internal consistency with high Cronbach's alpha. The questionnaire can be improved further by examining correlations between questions and objective outcomes for internal (criterion) validity in our population, such as between perception of benefit in exam performance and actual exam results.

\section{Conclusion}

Students regard obligatory reciprocal peer-teaching in the form of peer-led seminars similar to faculty teaching and have generally positive perceptions about the program. An overwhelming majority reported that they benefited both personally and professionally from leading seminars. Since it is a fundamental duty for doctors to teach and train younger generations, it is equally important for medical schools to prepare all students for such roles. Therefore, there is a lot of merit in a system that provides an opportunity for every student to become a peer-teacher.

\section{Ethical Approval}

The project was reviewed and approved by the internal review board (IRB) of Imam Muhammad Ibn Saud Islamic University.

\section{Acknowledgments}

We would like to thank all the students who participated by filling this research questionnaire.

\section{Author Contributions}

Saad Mohammed AlShareed generated the idea, conceived and designed the study. He also analyzed the data and wrote/ drafted the manuscript. Abdulrahman Yousef Aldayel, Hamid Mohammed Alghamdi, Mohammed Buraik Alosaimi, Muteb Mousa Alharbi, Abdulaziz Abdulrahman Aldayel and Hamad Abdulaziz Alhussain equally participated in collecting and analyzing the data and contributed to the writing and drafting of the manuscript. All authors approved the final version for publication, and they agree to be accountable for all aspects of this work.

\section{Disclosure}

The authors report no conflicts of interest in this work.

\section{References}

1. Leung KC. Preliminary empirical model of crucial determinants of best practice for peer tutoring on academic achievement. $J$ Educ Psychol. 2015;107(2):558-579. doi:10.1037/a0037698

2. Rees EL, Quinn PJ, Davies B, Fotheringham V. How does peer teaching compare to faculty teaching? A systematic review and meta-analysis. Med Teach. 2016;38(8):829-837. doi:10.3109/0142159X.2015. 1112888

3. Leung KC. An updated meta-analysis on the effect of peer tutoring on tutors' achievement. Sch Psychol Int. 2019;40(2):200-214. doi:10.11 77/0143034318808832 
4. Khalid H, Shahid S, Punjabi N, Sahdev N. An integrated 2-year clinical skills peer tutoring scheme in a UK-based medical school: perceptions of tutees and peer tutors. Adv Med Educ Pract. 2018;9:423-432. doi:10.2147/AMEP.S159502

5. ten Cate O, Durning S. Peer teaching in medical education: twelve reasons to move from theory to practice. Med Teach. 2007;29 (6):591-599. doi:10.1080/01421590701606799

6. Burgess A, McGregor D. Peer teacher training for health professional students: a systematic review of formal programs. BMC Med Educ. 2018;18(1):263. doi:10.1186/s12909-018-1356-2

7. General Medical Council. Developing teachers and trainers in undergraduate medical education. May 2011. Available from: https://www. england.nhs.uk/revalidation/wp-content/uploads/sites/10/2015/04/ developing-teachers-web.pdf. Accessed December 1, 2018.

8. World Federation for Medical Education. Basic Medical Education WfME Global Standards for Quality Improvement. Published 2015. Available from: https://wfme.org/publications/wfme-global-stan dards-for-quality-improvement-bme/. Accessed February 15, 2019.

9. Song Y, Loewenstein G, Shi Y. Heterogeneous effects of peer tutoring: evidence from rural Chinese middle schools. Res Econ. 2018;72 (1):33-48. doi:10.1016/j.rie.2017.05.002

10. Lelis C. Participation ahead: perceptions of masters degree students on reciprocal peer learning activities. J Learn Des. 2017;10(2):14-24. doi: $10.5204 /$ jld.v10i2.286

11. Bentley BS, Hill RV. Objective and subjective assessment of reciprocal peer teaching in medical gross anatomy laboratory. Anat Sci Educ. 2009;2(4):143-149. doi:10.1002/ase.96

12. Zaini RG, Bin Abdulrahman KA, Al-Khotani AA, Al-Hayani AMA, Al-Alwan IA, Jastaniah SD. Saudi meds: a competence specification for Saudi medical graduates. Med Teach. 2011;33(7):582-584. doi:10.3109/0142159X.2011.578180

13. Bin Abdulrahman KA, Saleh F. Steps towards establishing a new medical college in the Kingdom of Saudi Arabia: an insight into medical education in the Kingdom. BMC Med Educ. 2015;15(1):85. doi:10.1186/s12909-015-0366-6

14. Gazula S, McKenna L, Cooper S, Paliadelis P. A systematic review of reciprocal peer tutoring within tertiary health profession educational programs. Health Prof Educ. 2017;3(2):64-78. doi:10.1016/j. hpe.2016.12.001

15. Khaw C, Raw L. The outcomes and acceptability of near-peer teaching among medical students in clinical skills. Int J Med Educ. 2016;7:189-195. doi:10.5116/ijme.5749.7b8b

16. Burgess A, Dornan T, Clarke AJ, Menezes A, Mellis C. Peer tutoring in a medical school: perceptions of tutors and tutees. BMC Med Educ 2016;16:1. doi:10.1186/s12909-016-0589-1
17. Tai J, Molloy E, Haines T, Canny B. Same-level peer-assisted learning in medical clinical placements: a narrative systematic review. Med Educ. 2016;50(4):469-484. doi:10.1111/medu.12898

18. Benè KL, Bergus G. When learners become teachers: a review of peer teaching in medical student education. Fam Med. 2014;46 (10):783-787.

19. Alvarez S, Nikendei C, Schultz J-H. Development of a didactical training concept for peer tutors in gross anatomy. Anat Sci Educ. 2017;10(5):495-502. doi:10.1002/ase.1691

20. Hsiao YP (Amy), Brouns F, Bruggen JV, Sloep PB. Effects of training peer tutors in content knowledge versus tutoring skills on giving feedback to help tutees' complex tasks. Educ Stud. 2015;41(5):499512. doi:10.1080/03055698.2015.1062079

21. Shiozawa T, Hirt B, Celebi N, Werner A, Weyrich P, LammerdingKoeppel M. Does a combined technical and didactical training program improve the acceptance of student tutors in the dissection course? A prospective controlled randomized study. Ann Anat. 2010;192(6):361-365. doi:10.1016/j.aanat.2010.09.006

22. Abbot S, Graf AJ, Chatfield B. Listening to undergraduate peer tutors: roles, relationships, and challenges. Int J Teach Lear Higher Educ. 2018;30(2):245-261.

23. Al-Mously N, Salem R, AlHamdan N. The impact of gender and english language on the academic performance of students: an experience from new Saudi medical school. J Contemp Med Educ. 2013;1 (3):170. doi:10.5455/jcme.20130226121358

24. Akudo AH, Eberechukwu AS. Gender differences on medical students' perception of peer tutoring learning strategy on clinical skills training at macarthur clinical skills laboratory (mcsl). $\mathrm{Br} J$ Educ. 2018;6(5):1-8

25. Langan MA, Wheater PC, Shaw EM, et al. Peer assessment of oral presentations: effects of student gender, University affiliation and participation in the development of assessment criteria. Assess Eval High Educ. 2005;30(1):21-34. doi:10.1080/0260293042003243878

26. Tai J, Canny B, Molloy E, Haines T. Gender matters: students' perceptions of peer learning in clinical education. Focus Health Prof Educ. 2017;18(1):3-15. doi:10.11157/fohpe.v18i1.203

27. Hojat M, Glaser K, Xu G, Veloski JJ, Christian EB. Gender comparisons of medical students' psychosocial profiles. Med Educ. 1999;33 (5):342-349. doi:10.1046/j.1365-2923.1999.00331.x

28. Peterson DAM, Biederman LA, Andersen D, Ditonto TM, Roe K, Wilson RK. Mitigating gender bias in student evaluations of teaching. PLoS One. 2019;14(5):e0216241. doi:10.1371/journal.pone.0216241

29. Garland R. The mid-point on a rating scale: is it desirable. Mark Bull. 1991;2(1):66-70.
Advances in Medical Education and Practice

\section{Publish your work in this journal}

Advances in Medical Education and Practice is an international, peerreviewed, open access journal that aims to present and publish research on Medical Education covering medical, dental, nursing and allied health care professional education. The journal covers undergraduate education, postgraduate training and continuing medical education
Dovepress

including emerging trends and innovative models linking education, research, and health care services. The manuscript management system is completely online and includes a very quick and fair peer-review system. Visit http://www.dovepress.com/testimonials.php to read real quotes from published authors. 